\title{
Homens entre saúde e segurança pública: a violência nos hospitais de trauma
}

\author{
Helen Barbosa dos Santos* (1) \\ Henrique Caetano Nardi \\ Universidade Federal do Rio Grande do Sul, Porto Alegre, RS, Brasil
}

\begin{abstract}
Resumo: Em pesquisa de perspectiva etnográfica realizada em dois hospitais de trauma no município de Porto Alegre (RS), buscamos explicitar as convergências e divergências na intersecção entre práticas de saúde e de segurança pública voltadas aos homens vítimas de conflitos violentos. Analisaram-se as narrativas de múltiplos atores sociais (profissionais do campo da segurança pública e da saúde), bem como os fluxos de atendimento desses usuários de saúde e seus familiares. Os operadores conceituais centrais são inspirados nos estudos sobre tecnologias de poder (Michel Foucault, Giorgio Agamben), economia moral (Didier Fassin), masculinidades e violência. Concluímos que o hospital está firmemente articulado ao dispositivo da segurança pública por meio de práticas discursivas que fomentam a produção de masculinidades criminalizadas.
\end{abstract}

Palavras-chave: saúde, homens, segurança pública, criminalização, medicalização.

\section{Introdução}

Em meio ao cheiro de álcool, às portas e elevadores de metal, o vapor da cozinha que esfumaça a visão da cruz da igreja, lá no alto do hospital. Em meio ao sangue, ao cafezinho e ao salgado. Os uniformes verdes, os jalecos brancos, as fardas. Algemas, correntes, armas. Em frente ao detector de metais, entre banheiros da recepção. Em meio a cadeiras da sala de espera, após máquinas de diagnóstico e tecnologias de fazer sobreviver. Os instrumentos esterilizados, os papéis de prescrição e o sistema de informação. As vidas em suspensão.

Estamos no hospital de trauma em meio às tecnologias de saber-poder ${ }^{1}$ do Estado. Para profissionais de saúde, o hospital de trauma é o coração da cidade. Eles costumam relembrar com orgulho das histórias de vidas salvas em situações extremas, como quando os jovens queimados do caso da boate Kiss ${ }^{2}$ ficaram internados na única unidade de queimados de média e alta complexidade do Rio Grande do Sul no Hospital Pronto Socorro (HPS). "Todos saíram vivos", disse a gestora do hospital.

No entanto, frequentemente, outra fotografia emerge dentro do hospital: o traçado da cidade, nas suas divisões espaciais e geográfica, recortada em função da discriminação e da segregação entre os espaços elitizados e os espaços deteriorados, clandestinos e ilegais, define linhas de corte que recaem invariavelmente sobre o corpo cidadão (Endo, 2005). Esse processo torna-se visível quando

* Endereço para correspondência: helenpsi@yahoo.com.br

1 Dentro deste universo, no qual poder e saber estão intimamente ligados, o que se frisa, é que "não há constituição de poder sem constituição correlata de um campo de saber, nem saber que não suponha e não constitua, ao mesmo tempo, relações de poder" (Foucault, 1995, pp. 29-30).

2 O incêndio na boate Kiss foi uma tragédia que matou 242 pessoas e feriu 680 outras em uma boate na cidade de Santa Maria (RS). a violência antes limitada às zonas periféricas passa a ocupar o centro da cidade; é quando sobreviventes de confrontos em territórios armados pairam no hospital entre vida e morte.

Diríamos então que o hospital está mais para intestino do que coração. Esconda os corpos infames ${ }^{3}$ e traga-lhes assepsia. Sem intestino não há vida física, mas, desprovido de sua guarda, do que é sujo, torna o outro menos gente. A "barrigada", no Hospital Cristo Redentor, é o nome da infecção no intestino. "Se quiser atirar para matar, atire na barriga, não na cabeça. É morte lenta e gradual", desabafa a residente multiprofissional do Hospital Cristo Redentor. Não, não somos aquele resto de intestino que foi baleado, há meses aberto, onde a comida sai para o mundo sem digerir. A comida já estourando os sacos de colostomia e inundando a maca. Esquecido num quarto chamado isolamento, até que a auxiliar de limpeza prepare a cadeira e chegue para ouvir as histórias de vida de quem está com a morte decretada. Sobre o trabalho, a família, a juventude perdida. Quem quer ver/escutar? Tantas vezes escondidos sob tetos de pintura desfeita e mofados. Uma morte que é indissociavelmente política, social.

Trauma é dano ou lesão não previsto e indesejável. "Nenhum médico quer ficar costurando intestino, pontinho por pontinho, num hospital de trauma, é chato", diz uma das diretoras de um hospital de trauma. O intestino é impertinência: o trauma por armas de fogo exige complexidade terapêutica ${ }^{4}$, traz

3 No caso, os homens infames são os (ex)escravizados, os escarrados do mercado de trabalho, tidos como bandidos ou vagabundos. Quando não mortos fisicamente, o são socialmente e, se não forem absorvidos pelo desemprego, resta-lhes serem institucionalizados.

4 Um dos médicos do HPS revela que o trauma que atinge o intestino é recorrente e tem exigido para especialistas no campo da traumatologia novas técnicas de fazer sobreviver. Segundo ele, atualmente, no Rio de Janeiro, alguns se especializam em cursos, de como proceder às vítimas por fuzis de assalto (americano AR-15 e o russo AK-47). 
o risco de piora do quadro por infecção generalizada e requer um tempo maior de internação. Para além de sua dimensão vital, como metáfora, o intestino coloca em análise o hospital, que também é expurgo de problemáticas relativas à desigualdade social e lugar de práticas "presas na escuridão do baixo ventre" (Pereira, 2009 , p. 70), marcadas por processos de medicalização e criminalização que ocorrem para além de fluxos institucionalizados. Esse corpo do trauma é, sobretudo, aquele de homens negros, pobres e jovens no nosso país. No sistema prisional, eles são os chamados Caídos; em serviços de saúde com alto índice de mortalidade, são os Morredores. Perfurado ou lacerado, o corpo traumatizado ocupa o lugar ambíguo no cenário social.

Os relatos aqui analisados são fruto de uma etnografia em dois hospitais de trauma (Hospital de Pronto Socorro da Prefeitura Municipal de Porto Alegre e no Hospital Cristo Redentor do Grupo Hospitalar Conceição), referências para atendimento das urgências e emergências. Foi dada ênfase ao Hospital Pronto Socorro (durante três meses, de 20 a 30 horas de observação por semana) e observações das práticas profissionais no Hospital Cristo Redentor (HCR) enquanto estudo de campo pontual (totalizando 30 horas de observação).

No exercício de descrição densa, foi necessário, como diria Vinícius Carvalho Pereira (2009), "passar o texto a sujo, borrá-lo: tornar imprecisas e relativas as balizas que norteiam o pensamento do senso comum" (p. 11). A escrita precisa de feições, busca nomes e a coloca em seus pronomes. Mudando de modo rápido, rasante. Com o subir de escadas de profissionais de saúde, da emergência para a unidade de terapia intensiva (UTI), da UTI para a enfermaria, até que haja calmaria. Um amigável chimarrão nos quartos de custódia com Agentes da Superintendência de Serviços Penitenciários (Susepe) ou no silêncio petrificado de espera na emergência de saúde, com policiais militares em escolta aos homens feridos em conflitos violentos.

A etnografia ${ }^{5}$ (Fassin, 2017) oferece uma imagem distinta dos dispositivos de poder envolvidos nas políticas públicas e nas instituições. Busca a quebra de uma leitura reducionista, em que a responsabilidade ficaria de um lado apenas no domínio dos aparelhos sociais inanimados, ou mesmo na individualidade dos sujeitos como a culpabilização de profissionais por práticas em saúde discriminatórias.

Os fluxos de atenção em saúde em territorialidades múltiplas são percebidos pelo modo como são reconhecidas as dores, do que é vida e morte, do que entra, volta, nem saiu dali, entrou e nem foi visto. A escrita revive a circulação imprevisível pelo hospital para aceder, por meio dela, às problematizações sobre o fazer da saúde e

5 Didier Fassin (2013), em seu livro Enforcing Order, descreve em sua etnografia ações policiais voltadas a imigrantes que não só legitima como apoia e estimula os agentes a encabeçar policiamentos repressivos, ineficazes e contraprodutivos. Indicamos também o livro Writing the world of policing: the difference ethnography makes, escrito por pesquisadores de todos continentes, sobre o processo etnográfico de quem se aventurou pelas cercanias do policiamento e da segurança pública (Fassin, 2017). da segurança pública no hospital de trauma pelas práticas discursivas $^{6}$ dos profissionais.

Já é tempo das políticas sociais (entre elas a saúde) e das políticas penais deixarem de ser abordadas separadamente, tanto pelas ciências sociais como pelas políticas públicas. Parar de separar o corpo (corpo-família, corpo-profissional, corpo-usuário de serviços públicos), Estado social, Estado penal e a marginalidade urbana: vamos captá-los e explicá-los em conjunto, nas suas imbricações mútuas (Wacquant, 2013). Assim, na primeira parte deste artigo, demonstraremos a produção do potencial criminoso agenciada pelo "telefone sem fio": uma analogia sobre como a história de determinados usuários de saúde é recontada por meio de múltiplas vozes no hospital.

É de suma importância reconhecermos como determinados homens são tratados e têm suas vidas avaliadas e distinguidas por dimensões morais relativas à produção dos significados enquanto parte das tecnologias de governo. Para tanto, utilizaremos o conceito de economia moral retomado por Didier Fassin (2007, 2010, 2014, 2017) como operador analítico das práticas dos/as profissionais de saúde, das hierarquias colocadas em jogo e dos valores operados nas cenas de cuidado. As tecnologias de poder não se reduzem às relações de poder dos corpos de quem as executa e de quem deve acatar (até porque seus efeitos escapam a essa dualidade); antes, obedecem uma lógica que envolve instituições, redes multifacetadas e descompassadas de seus acontecimentos históricos.

Ainda, buscaremos narrar as minúcias das práticas discursivas presentes nas ações do estado penal, policiais civis e militares, assim como do vigilante, guardião das portas do hospital e do agente da Susepe, dono das chaves das correntes. É então que encontraremos mais um sinônimo para a palavra hospital: (1) intestino; (2) prisão. O hospital tem outro dono que se movimenta por entre as cercanias da saúde e com o poder disciplinar próprio à instituição. $\mathrm{O}$ território hospitalar também é porta de entrada para o sistema prisional, quando a gestão da população se mostra visivelmente ancorada nos dispositivos de segurança ${ }^{7}$. Desse modo, na segunda parte deste artigo,

6 Segundo Patrícia Medeiros (2008), os discursos formam os objetos de que falam, isto é, discursos são práticas, na medida em que constituem sujeitos. Eles falam e nos fazem falar, constituindo determinados modos de compreender, pensar e viver o que é violência urbana, por exemplo. Portanto os discursos não são subjetivos, mas subjetivam, na medida em que o indivíduo toma para si determinados discursos, considerados legítimos e verdadeiros, modificando-se e identificando as prerrogativas desse discurso como suas. Para Michel Foucault (2008), "o discurso é constituído de acontecimentos reais e sucessivos, e que não se pode analisá-lo fora do tempo em que se desenvolveu" (p. 224), bem como indica que há diferenças no interior de uma mesma prática discursiva, como se os sujeitos "falassem de objetos diferentes, tivessem opiniões opostas, fizessem escolhas contraditórias” (Foucault, 2008, p. 218).

7 Para Michel Foucault (2008), dispositivos de segurança seriam ações integradas de governo orientadas para a proteção da sociedade frente às condutas desviantes. Buscam apreender o ponto em que as coisas irão se produzir, por isso não envolvem somente instituições como a polícia, mas todas as instituições e funções sociais ramificadas que buscam cumprir os regulamentos e poderes estatais. Buscam fortalecer os elementos positivos da sociedade (favorecer o convívio social, dispor as construções de maneira adequada, permitir o escoamento da água e a circulação do 
analisaremos práticas que reiteram o caráter de austeridade no dispositivo de segurança que atravessa o campo das masculinidades racializadas dentro das comunidades que vivem a pauperização econômica e social. De maneira mais branda, no presente campo etnográfico, o poder soberano será analisado, por um lado, enquanto humilhação pública social e/ou no cerceamento de acesso aos direitos. Em seu extremo, mas não necessariamente sem a exposição do culpado, a execução, que emerge das narrativas sobre os sobreviventes que chegam aos serviços hospitalares. Interessa-nos pensar como essa violência produz novas demandas e desafios na atenção à saúde e como ela convoca o poder da segurança pública a se ocupar de uma cena local em que salvar vidas e o uso da força (em seus sentidos disciplinadores e/ou punitivos) não possuem combinação tática aparente.

\section{Fábulas de monstros: narrativas de profissionais de saúde e segurança pública.}

\begin{abstract}
Tu já foi na sala vermelha? Lá é muito tenso de atender, a pessoa está entre a vida e a morte, ai vem, de um lado, o policial militar dizendo que aquele cara é um bandido, e os técnicos do outro, numa lentidão para passar os instrumentos, fazer as coisas. O tempo de atendimento muda se o paciente é considerado do crime. (Médica residente)
\end{abstract}

O conceito de economia moral nos permite compreender como é produzida a subjetividade criminosa e os mecanismos de poder sobre a vida no contexto da saúde. Didier Fassin (2010) construiu um olhar crítico sobre a saúde pública, entendendo-a como precária, visto que suas ações compreendem uma dimensão moral do agir que determinado contexto define como o bem da humanidade.

Se o governo da conduta se pauta pela invenção de critérios do que deve ser o sujeito, ligando-o, marcando-o e identificando-o a um modelo de ser sujeito, são as relações de poder-saber que tornam possíveis a invenção desses critérios, sua materialidade (por meio de técnicas, procedimentos e práticas), seu sucesso ou mesmo a resistência a eles (Medeiros, 2008).

Nesse sentido, se as relações de poder entre distintas masculinidades se dão por reiteração, assimilação, releitura e/ou rechaço, não temos dúvida de que, no enlace pobreza e racismo, a intensa violência dirigida às masculinidades racializadas ${ }^{8}$ é efeito de uma condição de subalternização das sociedades pós

ar etc.) e frear os possíveis riscos que podem acometer a população (doenças, roubos, acidentes etc.) (Michel Foucault, 2008, p. 26). A população, assim, é apenas indiretamente atingida pelos dispositivos de segurança, o que ocorre na medida em que ela se relaciona com o espaço, com o meio. (Michel Foucault, 2008, p. 27).

8 Quando inferimos "masculinidades racializadas", explicitamos de que a raça humana é uma verdade construída pela ciência marcada pela metafísica da sustância, em malhas de saber poder que conferem ao corpo sua patologia, disposição genética e ou mental, justificando ações políticas de segregação e até mesmo o genocídio. escravistas (Rosa, 2006). Expostos à violência territorial armada, meninos e jovens apreendem performances masculinas que se posicionam sob a lógica do matar ou morrer, onde casa e rua se interpelam na produção de infâncias militarizadas ( Moura, 2007).

As masculinidades variam conforme o contexto social e histórico, e também são construídas simultaneamente em dois campos inter-relacionados de relações de poder: nas relações de homens com mulheres (desigualdade de gênero) e nas relações dos homens com outros homens (desigualdades também baseadas nos marcadores sociais como expressões do gênero e da sexualidade, raça, classe, etnia e geração). Entre distintas hierarquias de masculinidades, tipos de violências podem ou não ser reconhecidas como tal, sua inteligibilidade passa por múltiplos aspectos (Botton, 2007).

Quando bom e mau, vítima e culpado são posicionamentos dicotômicos rígidos, lados opostos separam os que são merecedores de cuidado daqueles que devem ser vigiados ou punidos. Haverá um momento em que os tradutores da dor', equilibristas de urgências, deverão escolher o destino do sofrimento do outro, o que é percebido como dor e o que é tomado como expressão de periculosidade.

"Trato todas as pessoas de maneira igual, sem distinção" (enfermeira). Estas proposições também foram proferidas pelas narrativas nos estudos de Sarti (2005), Deslandes (1999,), Deslandes, Minayo e Lima (2002), e Leal \& Lopes (2005). Para não fazer distinção, emerge o clássico enunciado: "Eu não quero saber da história do sujeito". Os autores Dejours (2007), Pitta (1991), Leal \& Lopes (2005) se referem aos mecanismos supracitados como estratégias para suportar algumas situações do cotidiano do trabalho. Apoiados nos estudos de Dejours (1997) e Sá (2005), considera-se que esta banalização da violência tanto pode ser o resultado de estratégias de defesa individuais e coletivas, por parte dos(as) profissionais, para lidarem com o sofrimento alheio, quanto reflexo de um fenômeno de banalização da injustiça social que atinge toda a sociedade.

Além da fragmentação da relação técnico de saúde-paciente, na qual o(a) trabalhador(a) tem seu trabalho fragmentado no parcelamento das tarefas, Leal e Lopes (2005) averiguaram que defesas psíquicas contra sentimentos de angústia ou revolta voltados aos homens hospitalizados em decorrência de agressão são acionadas a partir da despersonalização e negação da alteridade.

"Eu não quero saber da história do sujeito". Será? Observações sistemáticas de uma gama de personagens no hospital de trauma possibilitaram outros planos de passagem nas análises empreendidas. Contrariando os achados das autoras supracitadas, as histórias têm vida. Elas pegam elevadores, andam por salas de emergência,

9 A inteligibilidade da violência, marcada no corpo, se dá na medida da possibilidade de sua tradução pelos(as) profissionais nos termos da doença, fragmentada em suas dimensões biológicas, psíquicas e sociais (Deslandes et al., 2002; Sarti, Barbosa, \& Suarez, 2006). 
enfermarias abarrotadas e UTI. Elas incluem desde o trabalhador terceirizado da limpeza, o do refeitório, até o técnico de enfermagem e a(o) médica(o) especialista.

A justificativa de tratar todos de maneira igualitária faz parte de uma racionalidade discursiva que encobre a economia moral neste jogo relacional entre profissionais e "elementos suspeitos". O sujeito do crime também é material, construído no plano das narrativas, carregadas de moralidades que se articulam entre saúde e segurança pública, produzindo estratégias de vigilância e terapêuticas aos corpos considerados perigosos.

"Eles pressupõem muitas coisas sem saber de fato a história do sujeito", reclamam alguns residentes multiprofissionais, principalmente profissionais da psicologia e serviço social. Afirmam ainda que "os profissionais têm muita imaginação, têm muita história sobre usuários de saúde que nós não conseguimos desfazer, mesmo com todo esclarecimento, de quem acompanha de perto os pacientes e familiares".

Dois agentes da Susepe, em conversa no corredor em frente aos leitos de custódia do Hospital Cristo Redentor, afirmam que os profissionais de saúde, ao atenderem os homens custodiados pelo Estado, costumam "chegar num canto e perguntar baixinho: 'o que ele fez?'. Há uma curiosidade muito grande por parte deles" (agente da Susepe). Segundo estes profissionais, isso atrapalha o trabalho, pois "nem é querer humanizar o tratamento do preso, mas antes não deixar que ele vire motivo de chacota; é nosso dever não deixar o preso ser ridicularizado".

O que é tomado como verdadeiro dentro do hospital pode ser pensado como fruto de nossa vontade histórica da verdade, discursos que se pautam em saberes exteriores da sociologia, psicologia, psiquiatria e medicina para legitimar discursos de verdade. Mas onde há vontade de saber há poder e, diríamos também, violência. $\mathrm{O}$ discurso do verdadeiro, dessa forma, cria a aparência de libertar o sujeito do poder, do desejo e da violência. Mas, neste processo, o próprio discurso do verdadeiro não consegue reconhecer a sua vontade (o poder, o desejo, a violência) que o atravessa. Quanto mais tempo os homens permanecem dentro do hospital de trauma, maior o poder das narrativas. Histórias trágicas, tristes, algumas engraçadas. O enfermeiro vai para seu segundo livro sobre suas histórias na emergência de saúde: "Tá tudo aqui, na memória".

São quantas histórias? Quantas similaridades entre elas, elas se misturam e se perdem, se repetem. Muitas narrativas emergem como boletins. Eles falam do tipo de violência, do tipo de agressão, do sintoma, do diagnóstico, se viveu ou não. No meio disso, a valoração moral: "ele era vagabundo", "ele era estuprador", "ele disse que foi assaltado, que foi bala perdida, mas sabe, né?".

O mesmo contexto, segundo Brah (2006), pode produzir várias "histórias" coletivas distintas, diferenciando e ligando biografias por meio de especificidades contingentes. Toda narrativa contada já é parte do interlocutor e passará a ser dos que a escutarão. É ficcional porque nunca existirá uma verdade no fato que já não o é mais. Mas continua como acontecimento, produzindo múltiplas perspectivas sobre determinada realidade. O olhar sobre os sujeitos diz algo que é da vida da instituição; corpo-instituição e corpo-profissional vão, concomitantemente, se agenciando.

E nessas relações de poder entram os prestadores de serviços. Ao passo que circulam no hospital, estes são posicionados em escala hierárquica inferior ${ }^{10}$ aos profissionais de saúde. Transeuntes e figurantes, não raramente ascendem como mensageiros de um saber que se diferencia, e que não é possível, pelo saber especializado. Eles(as) trazem informações que advêm de territórios periféricos onde residem. Reconhecem nomes e feições no hospital de trauma; suas veridicções passam, então, a ter um valor produtivo.

E a informação sobre a vida do outro é, antes, narrativa. Conecta-se, de modo imprevisível, ouvidos e bocas de profissionais de saúde. E aqueles que têm como ferramenta principal a escuta (especialmente psicólogas(os) e assistentes sociais) transmutam-se, em muitos casos, em figurantes, nesses casos, destituídos de um saber sobre o sujeito.

Diante das cenas suscitadas, bem como nas pesquisas realizadas por Zanellato e Dal pai (2010) e Dal Pai (2011), confirma-se a fragilidade dos pressupostos "de humanização na saúde". A humanização ${ }^{11}$ engendrada por políticas públicas e discursos de saúde escapa a si mesma ao se eximir dos preceitos morais envolvidos que dividem os sujeitos entre aqueles por quem há um apego urgente e irracional e outros, cuja vida e morte simplesmente não importam. Mesmo que os(as) profissionais do serviço de emergência tenham conhecimento sobre a finalidade das propostas do acolhimento durante a classificação de risco, demonstram não compreender sua abrangência, identificando o acolhimento ${ }^{12}$ apenas como uma parte do atendimento, a pontualidade de um procedimento ou especialidade.

Atenção humanizada ${ }^{13}$ ? Eles dizem que nunca o farão, que o mais próximo disso é o respeito pelo preso,

10 Jessé Souza (2011) observou preconceitos de classe no contexto de um hospital a partir de técnicos de enfermagem, agentes que intermediam o contato dos pacientes com os médicos e outros profissionais. Pessoas que muitas vezes ascenderam da ralé ou de frações de classe mais próximas delas, mas também podemos incluir aqui os profissionais dos bastidores do hospital (como da limpeza, cozinha, copa, rouparia).

11 Enquanto política pública, a Política Nacional de Humanização existe desde 2003 e busca efetivar os princípios do Sistema Único de Saúde (SUS). Conforme Benevides e Passos (2005), humanizar a atenção e a gestão em saúde se apresenta como meio para a qualificação das práticas de saúde: acesso com acolhimento; atenção integral e equânime com responsabilização e vínculo; valorização dos trabalhadores e usuários com avanço na democratização da gestão e no controle social participativo. "O acolhimento diferencia-se da triagem, pois acolher se constitui numa ação de inclusão que não se esgota na etapa da recepção, mas que deve ocorrer em todos os locais e momentos" (Brasil, 2009, p 9).

12 "Aqui no hospital de trauma, estamos preocupados com a eficiência em salvar vidas. Não há como o hospital ficar discutindo pressupostos da humanização como fazem na atenção básica" (Gestora de um dos hospitais).

13 "A maioria das estruturas policiais brasileiras segue fortemente comprometida com valores antidemocráticos e com uma formação anti-humanista, características que constituem a antessala de práticas violentas e discriminatórias" (Rolim, 2007, p. 13). 
comumente o respeito pelo medo, sem muita abertura, senão vira "compadre ... tem colega meu que só falta assar um churrasco com o preso" (agente da Susepe). De fato, raramente conseguem algo para além do que percebemos, com suas táticas de gestão da vida, vigília e uma pitada (ou uma panela fervilhante) de castigo.

A postura política de que no "Brasil foram dados apenas direitos e deixou nossa sociedade assim, cheia de criminosos", é pauta comum. A economia moral é ligada a uma visão política da cultura institucional e indissociavelmente uma produção de masculinidades no interior dela.

O enfermeiro lembra em seus 30 anos de trabalho no hospital de trauma:

Antigamente, entravam vários bandidos importantes, assaltantes de banco. O Nego Pinto ${ }^{14}$ era um dos maiores criminosos do estado. Eles eram respeitosos, chegavam aqui, davam boa noite, bom dia, boa tarde. Passavam de cabeça baixa. Esses aqui, agora, já chegam se impondo. Quando eles apanhavam da polícia [civil], não era assim.

As teorias racistas são requeridas quando se deseja demonstrar a monstruosidade do criminoso ou do infrator, sua anormalidade, sua periculosidade, sua inferioridade biológica. O racismo é, desde o século XIX, uma doutrina política estatal usada para justificar a atuação violenta dos Estados modernos (Sanches, 2009). $\mathrm{O}$ reconhecimento político do corpo e das origens do sofrimento a ele associado é o que Fassin (2005), chama de biolegitimidade. Nesse sentido, Maluf (2005) afirma que a ausência dos poderes públicos obriga alguns sujeitos a recolherem a própria dor nas esferas do íntimo e do privado. Agem como se o confinamento da violência e, com ela, a reclusão e o emudecimento fossem seu único lugar aceitável e possível. Porém a "dor" também pode falar expressar vivamente uma história, assim como o "sofrimento" pode calar ou se apresentar sem linguagem. A medida da dor é a violência naturalizada no hospital de trauma. Fábula de monstros.

\section{Vamos levar ou vamos deixar morrer? Tecnologias de poder a homens feridos}

"A gente vive trazendo bandidos para o hospital e, infelizmente, eles tiram o lugar de pessoas de bem. Mas não temos o que fazer. Não podemos deixar morrendo" (policial militar). No entrelaçamento social-penal, a medicalização torna-se a outra faceta do Estado penal para a gestão da população quando práticas penais, historicamente, têm sido reproduzidas por meio de ações estratégicas de saúde (como fora na repressão à ociosidade no período da República

14 Nego-Chico, Sarará da Vó (Dornelles, 2008). O codinome explicita a raça como inventário do racismo. A animalização, a exacerbação físico-genital e a incompletude intelectual são vistas como inerentes aos homens negros (Conrado \& Ribeiro, 2017).
Velha, no combate ao alcoolismo no período getulista), com fins de normalização da população.

Pensando em entender as intervenções do poder político na saúde da população, como forma de governar a vida, o biopoder em Michel Foucault (2002) destaca as tecnologias de poder que buscam a produção social de corpos economicamente produtivos e politicamente dóceis. Divide-se em dois eixos principais: disciplina, o governo dos corpos dos indivíduos, e a biopolítica, que seria o governo da população como um todo.

$\mathrm{O}$ policiamento opera na ambiguidade entre a aplicação da lei associada à manutenção da paz e, em seu sentido mais antigo, a polícia compreende uma gama de intervenções humanas na regulação da sociedade, da saúde pública ao bem-estar infantil, à manutenção da ordem no controle da moral. É esse projeto de normalização da vida que, desde o século XVIII, abrange o que Michel Foucault chamou de biopolítica (Fassin, 2017).

Ao velho direito soberano de matar-expor à morte, ou multiplicar para alguns o risco de morte; decretar publicamente a morte política, a expulsão, a rejeição associa-se à biopolítica, à gestão da vida (Foucault, 2002). É necessário "fazer viver e deixar morrer" como formas de gestão da população. Mas veremos que o biopoder só coexiste na atualidade descrita, com as configurações do poder soberano em lógicas de "fazer morrer e deixar viver", como temos descrito aqui na injunção da saúde e da segurança.

Em tempos de controle biopolítico erigido em torno da "guerra às drogas", os aparatos de segurança próprios ao poder soberano convertem os sujeitos à fantasia de terror e da indispensabilidade de estratégias de contenção. Ocorre assim a legitimação da aplicação de uma metodologia de extermínio seletivo das camadas mais pobres (Sanches, 2009).

Eles não morrem mais aqui. Antigamente, no HPS era briga toda hora. Eles brigavam aqui dentro, era lotado de gente que vinha por violência urbana, agora vem muito pouco comparado a antes. Porque antes era briga. Agora é eliminação. A lógica é de eliminarem-se uns aos outros. Ou a policia matar e trazer para cá fingindo que não deixaram morrer. E a maioria nem chega no hospital, morrem na rua. (Enfermeiro há 25 anos no HPS)

Hospital é o território da rua, é intestino da cidade, que precisa digerir o que é escarrado dela. Mas rumina, enquanto tenta cuspir o que é percebido como alheio a seu interior. A cidade, tecida de instituições, é o fora que está sempre dentro. É quando operadores da brigada militar executam operações ambíguas. Eles são os "acompanhantes" (recolher a dor) dos homens no acesso à saúde, ao passo que "justiceiros" (punir a dor) da cidade em estado de emergência. Poder soberano e gestão da vida se fundem numa tensão entre um princípio de justiça em desacordo com a ordem democrática. 
Inumeráveis são as histórias percebidas nos itinerários terapêutico-penais proporcionadas pela pesquisa etnográfica. Rafael (23 anos) era um dos jovens internados no quarto de custódia do HPS. Com um dos lados da face inchado e ainda ensanguentado, verbaliza sua resignação aos outros dois usuários de saúde. Era a primeira vez que estava sendo "preso". Fora capturado com uma arma de Airsoft ${ }^{15}$ em tentativa de roubo a um policial militar fora do seu expediente de trabalho. Este, ao identificar a arma falsa, lançou dois tiros: um na face e outro pelas costas, no ombro de Rafael. O jovem em custódia confiou sua versão: "Eu estava estendido no chão me debatendo de dor e o policial à paisana que tentei assaltar e mais dois brigadianos olham pra mim e dizem: 'então, vamos deixar morrendo ou levamos?... Não podemos, ele só levou um tiro no rosto"”

Felipe (15 anos) presenciou o mesmo questionamento sobre o destino de sua sobrevivência pelos policiais militares. Foi parar no HPS na noite em que, após discutir com a namorada numa das festas do bairro, presenciou um confronto armado entre a polícia e traficantes do bairro. Seu braço começou a sangrar. Assustado, seguiu para casa para que sua mãe pudesse acompanhá-lo ao hospital até que, no meio do caminho, uma viatura parou o carro. Policiais militares arrancaram o menino do Uber e decretaram: "Agora tu vai morrer até sangrar". Mas como poderiam deixar morrendo se ele levou apenas um tiro no braço? Os policiais cortam o hospital do caminho e levam Felipe para fazer o corpo de delito. Lá o médico perito descobre: ele também havia levado um tiro no abdome. É preciso levá-lo às pressas ao hospital de trauma.

Foram três meses, seis cirurgias, dois choques anafiláticos. "Quase te vi morrer, rapaz", disse o médico. Situações assim causam sofrimento para as profissionais de saúde, como ao presenciar a mãe de Felipe desmaiar ao ver o filho entubado ou na luta para provar a inocência do filho e, assim, permitir que o menino passasse a uma maca sem correntes e o direito de ter a presença dela e da irmã como acompanhantes, em vez da custódia por agente socioeducativo.

Exceto pelo profissional da brigada militar que utiliza apenas algemas, os agentes da Susepe usam correntes de grosso calibre para prender os tornozelos às macas; estratégia adotada para que o profissional de saúde possa fazer os procedimentos necessários que envolvam (re)virar o corpo de bruços, de um lado ou de outro. Algemas para a chegada, o trânsito e a saída. Correntes para a permanência. O mesmo fazem os agentes socioeducativos na escolta para adolescentes em cumprimento de medida socioeducativa. Todos esses meninos-homens são os "custodiados" do hospital; nomenclatura que parece resolver a dissonância produzida entre os termos "preso" e "paciente"; bem como para adolescente e criminoso.

15 O airsoft é um esporte de ação que simula situações de combate. Para isso, utiliza armas de pressão que disparam bolinhas de plástico de $6 \mathrm{~mm}$ de diâmetro. No Brasil, o airsoft é regulamentado pelo Exército Brasileiro e a ponta laranja é exigida em todos os equipamentos.
Aparatos de ação contínua (algemas, correntes, armas, câmeras, sistema informatizado) têm efeito progressivo em direção à força de poder que se exerce antes sobre a mente de homens. Uma ortopedia não apenas para disciplinamento do corpo potencialmente perigoso, mas ao próprio corpo que exerce essa representação.

Mas intervenção penal e disciplina também fazem parte da economia do castigo. As instituições modernas pedem que os corpos sejam individualizados segundo seus escopos, e também para o adestramento, a observação e o controle. A disciplina que excede a organização do hospital, para o modo como a segurança pública se utiliza dessa territorialidade, permite executar as diferenciações da economia geral do poder. Os códigos e leis se inflam com novas regras. Assim, os mecanismos de disciplina também se intensificam, há mais vigilância, controle, classificação, busca pela patologia atrás do comportamento. Lei, disciplina e segurança se compõem em séries (Araújo, 2009).

A sobrevivência está em jogo. É matéria a ser testada pelo poder extralegal ao máximo, como a viatura policial, que ao transportar homens feridos em conflitos violentos se estende por horas, até que se chegue ao serviço de emergência. Um pacto com o destino: corpo vivo ou corpo morto. A dor do outro é instrumento para fazer justiça e, se não for feita, os criminosos devem pelo menos receber punição daqueles que os prendem.

No presente e multifacetado campo etnográfico, é importante entender em que consiste a vida nua; a primeira aproximação feita por Giorgio Agamben (2015) foi por meio da distinção realizada pelos gregos entre zoé e bios. Ressalta o pensador que tais termos eram utilizados para designar porções diversas do que é simplesmente compreendido como "vida". Enquanto zoé reportava-se ao simples fato de viver (fato este idêntico a todos os seres vivos, sejam homens ou qualquer outro animal), bíos é o nome atribuído a uma maneira específica de se viver, característica de um simples indivíduo ou de uma coletividade - em outras palavras, a bios simboliza "uma vida qualificada, um modo particular de vida" (Agamben, 2003, p. 9). Se no mundo clássico o espaço político é ocupado somente pela bios (vida qualificada), na modernidade, ele inclui em seu funcionamento à zoé (vida meramente biológica) - e o corpo, despido de substância política, passa a ser alvo de absolutamente qualquer intervenção: torna-se "vida matável", "vida indigna de ser vivida", pode ser assassinada ou torturada sem que se cometa um crime (Agamben, 2003). A vida passa, então, a coincidir exatamente com o espaço político, em que exclusão e inclusão, bios e zoé, direito e fato passam a habitar uma zona de indeterminação (Arán \& Peixoto, 2007). Assim, a estrutura de exceção se transformou no paradigma biopolítico dos governos atuais.

O Estado de exceção suspende o ordenamento jurídico, mas não desdenha deste ordenamento, ao contrário, compõe com ele a própria lógica da exceção: "o Estado de exceção representa a inclusão e a captura de 
um espaço que não está fora nem dentro, numa relação de dentro/fora, de inclusão/exclusão, de anomia/nomos" (Agamben, 2003, p. 56).

Nessas múltiplas estratégias de segurança agenciadas entre rua e hospital, prevalece o que chamamos de "fazer morrer travestido de deixar morrer". A negação ou supressão do sujeito enquanto vítima de um agravo em saúde é o fator que caracteriza o modelo punitivo de decisão (Carpentieri, 2012). É necessário pautar que, entre a vigência do sistema jurídico clássico e a instauração paulatina do sistema jurídico moderno, há um processo de redistribuição de toda a "economia do castigo". Em Vigiar e punir, Michel Foucault reconstitui tal processo, vinculando-o a um rearranjo da tecnologia da verdade no interior das práticas jurídicas. No caso do procedimento jurídico clássico (séculos XVI-XVIII), o suplício se centralizava como técnica de verdade e ato de punição, simultaneamente. Por seu efeito de verdade, "o suplício é uma técnica e não deve ser equiparado aos extremos de uma raiva sem lei", uma hierarquia do sofrimento imposta por um "código da dor" (Foucault, 1999, p. 30).

Punir às escondidas, num beco, numa esquina qualquer é um acordo secreto, um contrato informal entre as pessoas do bem e a polícia, de que se pode matar se necessário, mas também oferecer ao corpo um caminho institucional. A força extralegal é previsível e atraente (Ralph, 2017), talvez por isso a Susepe não seja o centro da segurança pública como acredita ser, apesar de estar entre as decisões extralegais e as do poder judiciário. $\mathrm{O}$ silenciamento das técnicas punitivas penais perpassa desde as indistinções entre o tiro nas costas e o tiro pelas costas ${ }^{16}$, até as perdas sociais e políticas que o encarceramento provoca na vida dos homens detidos e na de seus familiares. Outros exemplos poderiam ser especificados: em casos que ocorre a ausência do atendimento pré-hospitalar (Samu), ofertam-se decisões extralegais a cargo do policial militar. Enlaces punitivos são facilmente executados quando não há nada institucionalizado. Levar primeiro o sujeito que apresenta lesões após o confronto à Delegacia de Pronto Atendimento (DPPA) ou ao Hospital de Trauma? Como são decididos esses fluxos? Percebe-se, então, que o nada permitir ao sujeito (que seria) de direito também faz parte de uma economia da morte.

\section{Considerações finais}

Nossas considerações analíticas explicitaram como processos de medicalização e de criminalização são dois lados da mesma moeda num vasto terreno composto por múltiplos atores sociais envolvidos na atenção aos homens feridos em conflitos violentos. Iniciamos pela economia moral que movimenta práticas na saúde, ou seja, os modos de perceber os sujeitos, as valorações morais que embasam suas ações também se encontram no eixo relacional entre os(as) profissionais de saúde, com os(as) usuários(as) de saúde, mas também destes(as) com profissionais da segurança pública.

Em um segundo momento, exemplificamos como as operações ambíguas entre fazer viver e deixar morrer executadas por operadores da segurança pública revelam a ausência do estado nas zonas empobrecidas da cidade. Na indissociabilidade entre cidade e instituição, os conflitos armados no território das periferias atingem e tensionam o interior dos hospitais de trauma. A economia do castigo, em termos do contexto e dos sujeitos aos quais é dirigida, prevalece com maior intensidade quando se escondem e se afastam as operações policiais de quaisquer outras políticas públicas.

Situações que todos já sabem. Esse refinamento das técnicas punitivas diz do sofrimento dos homens detidos com consequências psicológicas e sociais das quais a sociedade não tomará conhecimento. Entender as estratégias de poder, especialmente as do poder soberano em tecnologias biopolíticas, é, sobretudo, perceber a punição metamorfoseada no circuito da segurança pública no campo da saúde.

\section{Men between health and public safety: violence in trauma hospitals}

Abstract: A research using ethnographic perspective was carried out in two trauma hospitals in the city of Porto Alegre/RS. We sought to describe the convergences and divergences of practices in the intersection between health and public safety fields regarding men injured in violent conflicts. Multiple social actors' narratives (professionals in the field of public security and health) were analysed, as well as the multiple paths of patients and their families in the search for health care. The central conceptual operators are inspired by studies on power technologies (Michel Foucault, Giorgio Agamben), Moral economics (Didier Fassin) and masculinities and violence (Waldemir Rosa). We conclude that the hospital system is firmly linked to the public security system through discursive practices that encourage the production of criminalized masculinities.

Keywords: health, men, public security, criminalization, medicalization.

16 Existe o tiro nas costas e o tiro pelas costas, aos quais caberia uma discussão no campo da criminologia mais aprofundada em outra ocasião. O crime deixará de existir quando se constitui em legítima defesa, conforme Artigo 25 do Código Penal. No entanto o que se constitui como justificativa para o uso de arma de fogo depende de uma série de contextos analisados caso a caso. Segundo relato de Rafael, após levar tiro na face, virou de costas para tentar fugir, foi então que levou um tiro no ombro (Greco, 2008). 


\section{Les hommes entre la santé et la sécurité publique : la violence dans les hôpitaux de traumatologie}

Résumé : Une recherche basée sur une perspective ethnographique a été menée dans deux hôpitaux de traumatologie de la ville de Porto Alegre / RS, nous avons cherché à décrire les convergences et divergences à l'intersection des pratiques de santé et de sécurité publique à l'encontre des hommes victimes de conflits violents. Des récits de plusieurs acteurs sociaux (professionnels de la sécurité publique et de la santé) ont été analysés, ainsi que les differents chemins utilisés par ces hommes et de leurs familles à la recherche de soins. Les opérateurs conceptuels centraux s'inspirent des études sur les technologies de pouvoir (Michel Foucault, Giorgio Agamben), I'économie morale (Didier Fassin) et les masculinités et la violence (Waldemir Rosa). Nous concluons que l'hôpital est solidement lié au système de sécurité publique par des pratiques discursives qui encouragent la production de masculinités criminalisées.

Mots-clés : santé, hommes, sécurité publique, criminalisation, médicalisation.

\section{Hombres entre la salud y la seguridad pública: violencia en hospitales de trauma}

Resumen: En una investigación desde una perspectiva etnográfica realizada en dos hospitales traumatológicos de la ciudad de Porto Alegre / RS, se buscó explicar las convergencias y divergencias en la intersección entre prácticas de salud y seguridad pública dirigidas a hombres víctimas de conflictos violentos. Se analizaran narrativas de múltiples actores sociales (profesionales del ámbito de la seguridad pública y la salud), así como los flujos de atención de estos usuarios de la salud y sus familias. Los operadores conceptuales centrales se inspiran en estudios sobre tecnologías de poder (Michel Foucault, Giorgio Agamben), Economía moral (Didier Fassin) y masculinidades y violencia (Waldemir Rosa). Concluimos que el hospital está firmemente vinculado al sistema de seguridad pública a través de prácticas discursivas que incentivan la producción de masculinidades criminalizadas.

Palabras clave: salud, hombres, seguridad pública, criminalización, medicalización.

\section{Referências}

Agamben, G. (2003). Homo sacer: o poder soberano e a vida nua. São Paulo, SP: Iluminuras.

Agamben, G. (2015). Estado de exceção: [Homo Sacer, II, I]. São Paulo, SP: Boitempo.

Arán, M., \& Peixoto, C. A., Jr. (2007). Vulnerabilidade e vida nua: bioética e biopolítica na atualidade. Revista de Saúde Pública, 47(5), 849-857.

Araújo, I. (2009). Foucault, para além de "Vigiar e Punir". Revista de Filosofia Aurora. Curitiba, 21(28), 39-58.

Benevides, R., \& Passos, E. (2005). A humanização como dimensão pública das políticas de saúde. Ciência \& Saúde Coletiva, 10(3), 561-571.

Botton, Fernando. B. (2007). As masculinidades em questão: uma perspectiva de construção teórica. Revista Vernáculo, 1(19-20), 109-120.

Brah, A. (2006). Diferença, diversidade, diferenciação. Cadernos Pagu, (26), 329-376.

Brasil. (2009). Acolhimento de classificação de risco nos serviços de urgência. Brasília, DF: Ministério da Saúde.

Carpentieri, J. R. (2012). Os direitos humanos e o direito penal: o papel do jurista em face do poder punitivo. Revista Direito Mackenzie, 6, 171-184.

Conrado, M. P., \& Ribeiro, A. A. M. (2017). Homem negro, negro homem: masculinidades e feminismo negro em debate. Estudos Feministas, 25(1), 73-94.
Dal Pai, D. (2011). Violencia no trabalho em pronto socorro: implicações para a saúde mental dos trabalhadores [Dissertação de mestrado]. Universidade Federal do Rio Grande do Sul, Porto Alegre, RS.

Dejours, C. (1997). Fator humano. Rio de Janeiro, RJ: FGV Editora.

Dejours, C. (2007) Banalização da injustiça social. Rio de Janeiro, RJ: Editora FGV.

Deslandes, S. (1999). O atendimento às vítimas de violência na emergência: prevenção numa hora dessas? Ciência \& Saúde Coletiva, 4(1), 81-94.

Deslandes, S., Minayo, M., \& Lima, M. (2002). Atendimento de emergência às vítimas de acidentes e violências no Brasil. Revista Panamericana de Saúde Pública, 24(6), 430-440, 2002.

Dornelles, R. (2008). Falange gaúcha. Porto Alegre, RS: Zero Hora.

Endo, P. C. (2005). A violência no coração da cidade: um estudo psicanalítico. São Paulo, SP: Escuta.

Fassin, D. (2005). Biopouvoir ou biolégitimité: splendeurs et misères de la santé publique. In M. C. Granjon (Ed.), Penser avec Michel Foucault: théories critiques et pratiques politiques (pp. 161-181). Paris: Karthala.

Fassin, D. (2007). When bodies remember: experiences and politics of AIDS in South Africa (Vol. 15). Berkeley: University of California Press. 
Fassin D. (2010). La raison humanitaire: une histoire morale du temps présent. Paris: Gallimard.

Fassin, D. (2014). Enforcing order: an ethnography of urban policing. Mana, 20(1), 204-206.

Fassin, D. (2017). Writing the world of policing: the difference ethnography makes. Chicago: University of Chicago Press.

Foucault, M. (1995). O sujeito e o poder. In H. L. Dreyfus \& P. Rabinow, Michel Foucault - uma trajetória filosófica: para além do estruturalismo e da hermenêutica (pp. 231249). Rio de Janeiro, RJ: Forense-Universitária.

Foucault, M. (1999). Microfísica do poder (14a ed.). Rio de Janeiro, RJ: Graal.

Foucault, M. (2002). Em defesa da sociedade: curso no Collège de France (1975-1976). São Paulo, SP: Martins Fontes.

Foucault, M. (2008). Segurança, território, população. São Paulo, SP: Martins Fontes.

Greco, R. (2008). Código penal comentado. Niterói, RJ: Impetus.

Leal, S., \& Lopes, M. (2005). A violência como objeto da assistência em um hospital de trauma: "o olhar" da enfermagem. Ciência \& Saúde Coletiva, 10(2), 419431. doi: 10.1590/S1413-81232005000200020

Maluf, S. W. (2005). Da mente ao corpo? A centralidade do corpo nas culturas da Nova Era. Ilha Revista de Antropologia, 7(1-2), 147-161.

Medeiros, P. (2008). Politicas da vida: entre saúde e mulher [Tese de Doutorado]. Pontifícia Universidade Católica do Rio Grande do Sul, Porto Alegre, RS.

Moura, T. (2007). Rostos invisíveis da violência armada: um estudo de caso sobre Rio de Janeiro. Rio de Janeiro, RJ: 7Letras.

Pereira, V. C. (2009). Literatura e abjeção: um estudo da imagem das fezes na obra de Rubem Fonseca [Dissertação de Mestrado]. Universidade Federal do Rio de Janeiro, Rio de Janeiro, RJ.

Pitta, A. (1991). Hospital: dor e morte como oficio. São Paulo, SP: Hucitec.
Ralph, L. (2017). Alibi: The extralegal force embedded in the Law (United States). In D. Fassin, Writing the world of policing: the difference ethnography makes (p. 248). Chicago: The University of Chicago Press.

Rolim, M. (2007). Caminhos para a inovação em segurança pública no Brasil. Revista Brasileira de Segurança Pública, 1(1), 32-47.

Rosa, W. (2006). Homem preto do gueto: um estudo sobre a masculinidade no rap brasileiro [Dissertação de Mestrado]. Universidade de Brasília, Brasília, DF.

Sá, M. C. (2005). Em busca de uma porta de saida: os destinos da solidariedade, da cooperação e do cuidado com a vida na porta de entrada de um hospital de emergência [Tese de Doutorado]. Universidade de São Paulo, São Paulo, SP.

Sanches, C. A., Jr. (2009). Apontamentos gerais sobre a tortura na contemporaneidade: as contribuições de Michel Foucault e Giorgio Agamben. Revista LEVS, (4), 1-12.

Sarti, C. (2005). O atendimento de emergência a corpos feridos por atos violentos. Physis: Revista de Saúde Coletiva, 15(1), 107-126.

Sarti, C. A., Barbosa, R. M., \& Suarez, M. M. (2006). Violência e gênero: vítimas demarcadas. Physis: Revista de Saúde Coletiva, 16(2), 167-183.

Souza, J. (2011). A ralé brasileira: quem é e como vive. Belo Horizonte, MG: Editora UFMG.

Zanelatto, D. M. Dal Pai, Daiane. (2010). Práticas de acolhimento no serviço de emergência: a perspectiva dos profissionais de enfermagem. Ciência, Cuidado e Saúde, $9(2), 358365$.

Wacquant, L. (2013). Punir os pobres: a nova gestão da miséria nos Estados Unidos (3a ed.). Rio de Janeiro, RJ: Revan.

Recebido: $13 / 01 / 2018$

Revisado: 08/07/2021

Aprovado: 14/07/2021 